\title{
DESAFIOS PARA UMA CIDADE SER CRIATIVA EM UMA SOCIEDADE (PÓS)PANDÊMICA: UM ESTUDO SOBRE OURO PRETO (MG) BRASIL
}

CHALLENGES FOR A CITY TO BE CREATIVE IN A (POST) PANDEMIC SOCIETY:

A STUDY ON OURO PRETO (MG) BRAZIL

\section{Magnus Luiz Emmendoerfer}

Doutor em Ciências Humanas: Sociologia e Políticas pela Universidade Federal de Minas Gerais (Belo Horizonte/Brasil). Professor Associado do Programa de Pós-Graduação em Administração Pública e Líder do Grupo de Pesquisa em Gestão e Desenvolvimento de Territórios Criativos do Núcleo de Administração e Políticas Públicas na Universidade Federal de Viçosa (Viçosa/Brasil).

E-mail: magnus@ufv.br

ORCID: https://orcid.org/0000-0002-4264-8644

Lattes: http://lattes.cnpq.br/0919407313173824

\section{Alexandre Sette Abrantes Fioravante}

Doutorando em desenvolvimento econômico e políticas sustentáveis no Instituto de Economia da Universidade Estadual de Campinas (Campinas/Brasil). Pesquisador no Grupo de Pesquisa em Gestão e Desenvolvimento de Territórios Criativos do Núcleo de Administração e Políticas Públicas na Universidade Federal de Viçosa (Viçosa/Brasil).

E-mail: alexandresettefioravante2@gmail.com

ORCID https://orcid.org/0000-0002-0180-249X

Lattes: http://lattes.cnpq.br/4822638220453423 


\section{Brazilian

\section{RESUMO}

O ano de 2021 foi designado pelas Nações Unidas como o Ano Internacional da Economia Criativa para o Desenvolvimento Sustentável. Neste sentido, o objetivo deste estudo foi analisar se Ouro Preto, Minas Gerais, pode ser considerada uma cidade criativa a partir da imagem percebida pelos turistas e habitantes. Ouro Preto é reconhecida mundialmente pela UNESCO pelo título de patrimônio Histórico da Humanidade, devido uma série de segmentos relacionados à economia criativa, que atraem turistas do mundo inteiro, e pela sua efervescência cultural. Complementando as análises propostas neste estudo, busca-se tecer reflexões em torno da pandemia da Covid-19 e de seus reflexos para as cidades criativas, existentes ou iminentes. Para tanto, foram realizadas pesquisas documentais e de campo, com questionários no centro histórico da cidade em estudo. Os dados coletados foram tratados por meio da técnica de análise de conteúdo. Como resultados, observou-se que faltam conexões justamente onde encontramos muita criatividade e cultura. Somado a isso, há uma carência de projetos culturais transversais a todos os setores e falta inovação, não apenas tecnológica, mas para lidar com problemas sociais a fim de tornar esta cidade um espaço mais inspirador à imaginação, à criatividade e ao turismo sustentável. Como conclusões, para superar os desafios impostos pela pandemia da Covid-19, serão necessários esforços conjuntos entre o setor público, privado e sociedade civil organizada que trabalhem estratégias em diversas frentes, em especial quando se trata das "conexões", que foi o elemento mais impactado.

Palavras-chave: Território Criativo. Criatividade. Cultura. Setor Criativo. Política Pública.

\section{ABSTRACT}

The year 2021 has been designated by the United Nations as the International Year of the Creative Economy for Sustainable Development. In this sense, the objective of this study was to analyze if the city of Ouro Preto, Minas Gerais, Brazil can be considered a creative city from the image perceived by tourists and locals. Ouro Preto is worldwide recognized by UNESCO for the Historical heritage of humanity title, and because concentrates a great number of sectors related to the creative economy, with attracts tourists from all around the world, and for its cultural effervescence. Complementing the analysis proposed in this study, will be done considerations on the pandemic COVID-19 and its consequences for creative cities, existing or imminent. As methods were done documental research and field investigation using questionaries in the historic city center. The collected data were treated by the technique of content analysis. As results, were found a great lack of connections precisely where can be find a lot of creativity and culture. There is a lack of cultural projects cut across all sectors and a lack of innovation, not only the technological ones, however innovations to deal with social problems, making the city a more inspiring place to the imagination, creativity and sustainable tourism. As conclussions, overcoming the challenges imposed by the COVID-19 pandemic, joint efforts between the public, private and organized civil society that work on strategies on several fronts will be necessary, especially when it comes to "connections", which was the element that was most impacted.

Keywords: Creative Territory. Creativity. Culture. Creative Sector. Public Policy. 


\section{Brazilian \\ Creative Industries}

\section{INTRODUÇão}

A ocupação desordenada e vertiginosa das cidades data de tempos recentes. Há um século, somente $4 \%$ da população mundial residia em áreas urbanas. Hoje, com mais da metade da população mundial vivendo em zonas urbanas, o entendimento em torno da formação das cidades e dos territórios demanda uma visão mais ampla em torno de aspectos como regras de convívio coletivo, conceitos de organização, de valorização e de usos do espaço público da cidade, bem como de suas relações com os aspectos sociais, ambientais e econômicos locais.

As cidades, centros de riqueza, prosperidade e harmonia social, podem ser entendidas como organismos vivos, lugares onde as pessoas se conectam; mas que muitas vezes se traduzem em locais de pobreza, exclusão e isolamento social, poluentes e violentos. Por conta disso, existe uma preocupação em nível mundial em busca de cidades melhores, de um modelo de organização espacial que promova uma situação de bem-estar socioeconômico adequada para os seus habitantes, que seja ecologicamente correta e inovadora para dar conta de solucionar os problemas cotidianos.

Durante a segunda metade do século XX, com o advento da chamada era pós-industrial, as cidades foram transformadas pela sociedade e a economia do conhecimento. Essas transformações trazem novas formas de comunicação e de acesso à informação, pela economia dos serviços, entre outros fatores. A cidade pós-industrial tem em sua base o reconhecimento do capital humano, tanto em termos sociais quanto econômicos. Especificamente, ao longo desta última década, a criatividade e a cultura têm crescentemente ganhado espaço entre as discussões sobre desenvolvimento, economia e sustentabilidade.

O papel das cidades e o sentido envolto nelas vêm sofrendo mutações principalmente devido ao movimento da globalização. Na atualidade, as cidades representam mais do que o palco das relações econômicas que nela se desenrolam, mas também o lugar onde se desenvolvem as relações sociais, a cultura local, os hábitos e atitudes da população. São esses aspectos que conferem identidades únicas a estes espaços e que dão alma a uma cidade.

Segundo Ashton (2018), o estudo das cidades se envereda por várias ciências e se interconecta com distintas áreas de pesquisas. Nos últimos anos, muitos estudiosos das mais diversas áreas do conhecimento têm buscado explicar e compreender as cidades, entre estes, Hall (2000), Canclini (2008), Florida (2011), Landry (2013), Howkins (2013), entre outros.

Florida (2011) defendeu a necessidade da atração e retenção de uma classe de profissionais criativos para o sucesso e desenvolvimento das cidades. Landry (2013) criou o termo e o conceito das cidades criativas que vai além do aspecto geográfico, dando ênfase à criatividade como ativo. Segundo Ashton 


\section{Brazilian \\ Creative Industries}

(2018), as cidades eram vistas como espaços para pensar, planejar e agir com imaginação (na criação da própria cidade), criando oportunidades e resolvendo seus problemas locais de forma criativa.

A discussão acerca das "cidades criativas" vem despertando atenção e interesse crescente em vários países entre formuladores de políticas públicas, urbanistas, sociólogos, gestores públicos e economistas, em que se estabelece uma estreita relação com o conceito da chamada economia criativa como estratégia e políticas públicas para o crescimento em nível local (VITÓRIA et al., 2021) e desenvolvimento sustentável.

Contribuíram para o fomento destas discussões vários fatores, como a busca por um novo modelo de organização urbana, agregando benefícios sociais, econômicos, culturais e ambientais. Por trás disso, há o entendimento de que a competitividade econômica das regiões depende de inovação (de processos, produtos, sociais, culturais etc.) e de que a inovação é diretamente proporcional à criatividade, em termos de máxima: quão mais criativo for o ambiente no qual vivemos, mais realizados seremos, mais resolvida será a sociedade e mais pujante será a economia.

O tema das cidades criativas ganhou mais expressão internacional na agenda global de desenvolvimento com a criação, em 2004, pela Organização das Nações Unidas para Educação Ciência e Cultura - UNESCO -, da Rede de Cidades Criativa (UNESCO Creative Cities Network - UCCN), para promover a cooperação com e entre cidades que identificaram a criatividade como um fator estratégico para o desenvolvimento urbano sustentável. A criação desta rede fortalece o papel e importância deste tema para a implementação dos 17 Objetivos de Desenvolvimento Sustentável da Agenda 2030 das Nações Unidas, notadamente o Objetivo 11 sobre cidades e comunidades sustentáveis (UNESCO, 2019).

Mas o que é economia criativa e como ela se relaciona com as cidades criativas? Estes conceitos serão trabalhados mais detalhadamente no referencial teórico. O termo Economia Criativa, pelo menos para os países em desenvolvimento, figura-se carente de delimitações, talvez pela importação do termo e pela incipiente atuação estatal no setor. Porém, desperta a atenção de vários países ao redor do mundo, ao longo da última década e, de forma mais profunda, a partir da segunda metade desta. A crescente atenção ao tema está ligada à busca por um modelo de organização urbana coerente com um paradigma socioeconômico em transição, que passa do modelo industrial tradicional para uma economia guiada pelo setor secundário.

A competitividade de regiões está diretamente dependente das inovações em seus processos e produtos tanto no âmbito social quanto cultural. Conforme ressaltado por Reis (2012), o que caracteriza uma "cidade criativa" é a sua capacidade de estar se transformando continuamente no seu contexto socioeconômico com base na criatividade daqueles que a habitam e em conexões com suas singularidades culturais e suas vocações econômicas. 


\section{Brazilian \\ Creative Industries}

No contexto em que a pandemia da Covid-19 trouxe impactos sem precedentes, e ainda não totalmente mensuráveis, nas economias, sociedades e sistemas políticos em todo o mundo, será cada vez mais necessário que as cidades se mostrem criativas, sendo capazes de apresentar soluções para os problemas atuais do cotidiano das pessoas. Para tanto, é importante que uma estrutura de governança esteja bem estabelecida nestes espaços, capaz de envolver todos os agentes interessados em promover o desenvolvimento (EMMENDOERFER, 2019).

Com base nestes argumentos, este artigo foi direcionado para o estudo da cidade de Ouro Preto. 0 objetivo foi analisar se a cidade pode ser considerada uma cidade criativa a partir da imagem percebida pelos turistas e habitantes, verificando se aspectos pré-pandêmicos são ainda pertinentes em uma sociedade pós-pandêmica.

A cidade de Ouro Preto é reconhecida mundialmente pela UNESCO como Patrimônio Cultural da Humanidade, devido uma série de segmentos relacionados à economia da cultura e criativa que atraem turistas do mundo inteiro e pela sua efervescência cultural. Neste artigo, parte-se da premissa de que Ouro Preto, em virtude das características da cidade, possui potencial relevante para figurar-se como cidade criativa. Ouro Preto, a título de ilustração não única, possui diversos agentes culturais pertinentes e autodesignados como pertencentes à economia criativa local (cf. http://mapas.cultura.gov.br/), e estes, associados à uma diversidade cultural ímpar, podem proporcionar um ambiente favorável à criatividade, atraindo indivíduos e contribuindo para o estabelecimento de ligações entre pessoas e seus espaços. Porém, esses atributos existentes em Ouro Preto, considerados pré-pandêmicos, seriam ainda pertinentes e adequados para torná-la uma Cidade Criativa numa sociedade pós-pandêmica, ou seja, após o reconhecimento mundial da pandemia da Covid-19?

Uma série de questionamentos serviram de base para o desenvolvimento deste trabalho e foram explorados para melhor entendimento do potencial de contribuição das "cidades criativas" para o desenvolvimento mais sustentável. Que estratégias devem estar interligadas quando tratamos de cidades criativas? Para tanto, é necessário esclarecer: o que é uma cidade criativa e qual a importância em promover o desenvolvimento destas cidades? Quem devem ser os responsáveis por alavancar e superar o desafio de transformar estes espaços urbanos em algo mais do que uma aglomeração e espaço de trocas econômicas em um ambiente mais criativo?

Adicionalmente, procurou-se refletir sobre as percepções relativas ao papel desempenhado pelo turismo na cidade. Entende-se que este setor desencadeia múltiplas associações positivas: como catalisador de negócios locais, de desenvolvimento do setor de serviços e do aumento da demanda cultural, garantindo ainda a viabilidade de muitos projetos culturais que se mostrariam insustentáveis, 


\section{Brazilian \\ Creative Industries}

caso dependessem apenas da demanda, como promotores do encontro de ideias e diversidades (Cf. EMMENDOERFER, 2019).

Além disso, buscou-se tecer algumas reflexões em torno da pandemia de Covid-19 e seus reflexos para as cidades criativas, existentes ou eminentes. Nesse artigo, adota-se a ideia já apresentada por diversos autores (FLORIDA, 2011; HOWKINS, 2013; REIS, 2012; HARTLEY, 2005; SIMAS, 2009; PRATT, 2008; EVANS, 2003; CRUZ, 2010) de que apenas aqueles espaços, regiões, cidades ou nações que apostem em uma estratégia de fomento à economia criativa, estreitamente em conexão com inovações, na cultura e no conhecimento, numa classe mais criativa, poderão fomentar mecanismos de desenvolvimento urbano mais sustentáveis.

Este artigo está estruturado em seis seções, incluindo esta introdução e as considerações finais. Na sequência são apresentados os procedimentos metodológicos empreendidos nesta pesquisa empírica. Depois, no referencial teórico, discute-se os conceitos e definições sobre economia criativa e cidades criativas. Prosseguindo, são apresentados os resultados e discussões acerca deste estudo, visando inspirar outras pesquisas sobre o objeto em voga.

\section{PROCEDIMENTOS METODOLÓGICOS}

Este trabalho seguiu uma abordagem qualitativa e quantitativa, e para tanto, utilizou de dados primários e secundários. Os dados primários foram coletados por meio de pesquisa de campo exploratória de natureza indutiva realizada no centro histórico de Ouro Preto (Cf. EMMENDOERFER, 2019), com a realização de entrevista e por meio da aplicação de questionários estruturados aplicados a turistas. A amostra de dados primários foi constituída de 60 participantes, escolhidos aleatoriamente por acessibilidade e disponibilidade, anos antes da instauração da pandemia da Covid-19.

0 instrumento de coleta abarcou questões abertas e fechadas, que tratavam das motivações e preferências dos entrevistados e das frustações e fatores críticos observados, no intuito de estabelecer um espaço interativo de diálogo com o poder público local e inspirado no trabalho de Madureira e Branco (2001), neste estudo com representantes do poder público local responsáveis pela área de turismo e de cultura. A partir dos dados coletados, foram expostos os pontos críticos, os futuros projetos e as principais demandas nos campos da criatividade, cultura e turismo do município, no intuito de conhecer com alguma profundidade todo este contexto (GODOI; MATTOS, 2010).

Neste caso, aplicou-se a entrevista com roteiro semiestruturado pela possibilidade de ao mesmo tempo ter um roteiro pré-definido, o que evita desvios do foco da pesquisa, e por proporcionar também, ao entrevistador, a flexibilidade para ordenar e formular as perguntas durante a entrevista, na qual informante 


\section{Brazilian \\ Creative Industries}

tem a possibilidade de discorrer sobre o tema proposto (GODOI; MATTOS, 2010). Essencialmente, as perguntas versavam sobre as motivações dos participantes da pesquisa em conhecerem a cidade, bem como o seu entendimento acerca da economia criativa.

Posteriormente estes dados foram analisados por meio da técnica de Análise de Conteúdo (AC), utilizando-se da técnica de análise categorial por temas e por subcategorias. Os procedimentos foram baseados na proposta de Laville e Dione (1999). A técnica foi aplicada em três etapas cronológicas: a préanálise, como já mencionado, em que foram feitas as definições de materiais e procedimentos a serem seguidos; a exploração do material e tratamento dos resultados (aplicação dos procedimentos escolhidos na pré-análise); e tratamento dos resultados e interpretação (geração de inferências que vão construir os resultados da investigação).

Para Bardin (2015), a codificação dos dados brutos do conteúdo pesquisado permite ao analista atingir uma representação acerca das características da realidade investigada e assim possibilitar a organização dos dados a fim de apontar resultados em relação aos objetivos propostos. Os resultados da pesquisa foram trabalhados em dois blocos: Motivações e preferências dos entrevistados e frustações e fatores críticos encontrados na cidade. A partir daí foram estabelecidas as subcategorias.

Para a definição destas, foram considerados os apontamentos obtidos pelos questionários de dentro de cada um destes dois blocos, buscando a identificação dos sentidos dos relatos, sendo reunidos por similaridade. Foram estabelecidas cinco subcategorias para o primeiro bloco (Patrimônio cultural e arquitetura; Artesanato e artes, pesquisa desenvolvimento e fruição de conhecimento, ecologia e meio ambiente e outros). Para o segundo bloco foram estabelecidas as categorias: mobilidade, programação e organização das atividades turísticas, planejamento urbano, manutenção do patrimônio e capacitação.

Para complementar a pesquisa, além dos dados primários, foram coletados dados secundários, por meio de pesquisa bibliográfica em trabalhos publicados no meio acadêmico (VITÓRIA; EMMENDOERFER, 2021) e científico (como teses, dissertações e artigos) nas áreas de economia criativa, cidades criativas, cultura e turismo. Os dados foram então cotejados, uma importante prática de pesquisa para se extrair e articular os dados obtidos nos documentos, entrevista e questionário com os dados obtidos nas bibliografias desta pesquisa. Assim, essa análise qualitativa foi importante para organizar e apresentar os resultados na seção de resultados e discussão. A seguir são apresentados a fundamentação teórica com os argumentos, teorias e preceitos acerca do tema que serviram de base para a condução deste estudo e para a interpretação dos dados encontrados. 


\section{Brazilian

\section{CIDADES CRIATIVAS: ANTECEDENTES, EIXOS E CONCEITOS}

O tema economia criativa tem sido tratado por uma gama de autores, que têm estudado também as atividades da indústria criativa e suas relações com os aspectos sociais e culturais em países desenvolvidos (FLORIDA, 2011; CAVES 2000; UNCTAD, 2010; HARTLEY, 2005). A economia criativa tem representado para Reis (2008), o emblema de um novo ciclo econômico, que surge como resposta a problemas globais renitentes. Esta nova condição traz a cultura como base e a tecnologia como veículo propulsor, a organização dos mercados em redes, as parcerias entre os agentes sociais e econômicos, a prevalência de aspectos intangiveis da produção, o uso das novas tecnologias para a produção, distribuição e/ou acesso aos bens e serviços e a unicidade da produção, fortemente ancorada nas singularidades do local.

É importante destacar que a dedicação às atividades criativas não deve ser vista como nenhuma novidade, pois desde a antiguidade as pessoas já se dedicavam a atividades criativas. 0 que difere uma época da outra é que na atualidade estas atividades estão se tornando predominantes, prova disto seriam as estruturas econômicas criadas em torno destas como formas de suporte. Apropriando-se das ideias clássicas de Hirschman (1961), sobre os efeitos de encadeamento, poder-se-ia dizer que as atividades criativas possuem um grande poder de encadeamento "pra traz" e "pra frente", ou seja, tem condição ou capacidade de ser responsável pela indução de novas atividades e de procura, levando assim ao surgimento de outros setores ainda mais recentes em prol do desenvovimento dos territórios.

O contexto criativo engloba tanto aspectos econômicos quanto socioculturais, interagindo com objetivos tecnológicos e também com áreas como turismo e educação, o que pode incrementar o grau de complexidade às relações existentes neste meio. Quanto a estes aspectos, a UNCTAD (2018) acrescenta que cultura e criatividade desempenham papel fundamental no desenvolvimento urbano sustentável. A contribuição de ambas está calcada na diversificação da economia e geração de empregos, mas também na melhoria da qualidade de vida dos cidadãos ao participarem do tecido social e da diversidade cultural de uma cidade. Da mesma forma, ao estimular a participação cultural e regenerar os espaços públicos, a criatividade também se torna um facilitador de inclusão e bem-estar (UNCTAD, 2018).

As primeiras menções ao termo "cidades criativas" envolvem profissionais, sobretudo concentrados no eixo Austrália - Reino Unido - Estados Unidos-Canadá, que, a rigor, representa também o espaço de gênese da discussão da temática das indústrias criativas e, de forma mais ampla, da economia criativa (BRITISH COUNCIL, 2005), tendo como base principal, áreas de conhecimento como economia, arquitetura, planejamento urbano e sociologia. Os países deste eixo foram pioneiros em procurar estimular 


\section{Brazilian \\ Creative Industries}

a competitividade por meio da exploração dos benefícios que a criatividade pode proporcionar em nível de cidades.

Segundo Cruz (2010), a origem da palavra criatividade está relacionada à existência, o criar, inventar, lidar criativamente com problemas que possam parecer sem solução. Os conceitos de criatividade e inovação não devem ser confundidos, apesar de muitas vezes serem. Há uma relação estreita entre criatividade e inovação, mesmo assim, ambas devem ser vistas e entendidas como processos distintos. A criatividade é o processo através do qual novas ideias são produzidas, enquanto a inovação é o processo por meio do qual as novas ideias são implementadas. Ou seja, criatividade é pré-condição para que haja inovação.

Nesse contexto, é importante refletir sobre dois pontos: quais fatores contribuíram para o surgimento das cidades criativas? E o que torna uma cidade criativa?

Em se tratando do primeiro ponto, Ashton (2018) argumenta que entre os fatores que contribuíram para o surgimento das cidades criativas estão as grandes transformações observadas em nível mundial, a saber: globalização; tecnologias de informação; aumento significativo da população em cidades; redução da sustentabilidade nos grandes centros urbanos. Para essa autora, esses fatores passaram a demandar novas necessidades e novas urgências, como: a busca por novos caminhos para acelerar o desenvolvimento das cidades; busca por um novo modelo de organização urbana; necessidade em manter a competitividade econômica das cidades e regiões e urgência para inovar na produção de bens e serviços (ASHTON, 2018).

Em relação ao segundo fator, apesar de não haver consenso nas respostas para esta questão, vários autores (LANDRY; BIACHINI, 1995; HOWKINS, 2013; SIMAS, 2009; REIS, 2012; FLORIDA, 2011) apresentam suas ideias sobre o que é uma "cidade criativa". Uma cidade criativa pode ser análoga a uma história contada de forma encantadora ou, segundo Howkins (2013), é um lugar libertário de geração de idéias a partir de aprendizados e adaptações. Uma cidade criativa deve ser vista como um ambiente voltado para a superação de problemas e, portanto, está constantemente em processo de transformações materiais e simbólicas.

Apesar das distintas definições e ideias acerca do tema, neste estudo trabalhou-se com a percepção adotada por Reis (2012) de "cidade criativa" como aquela alicerçada sobre os eixos da inovação, conexões e cultura. Ainda, este estudo apropriou-se das reflexões de Florida (2011) sobre a teoria do capital criativo para explicar a importância de pessoas criativas no crescimento e desenvolvimento econômico urbano e regional. Nessa perspectiva, as pessoas criativas preferem lugares mais diversificados, tolerantes e abertos a novas ideias. Quanto maior e mais diversificada a concentração de capital criativo, maior será a capacidade de inovar, de criar negócios de alta tecnologia, de gerar empregos e de crescer economicamente 


\section{Brazilian \\ Creative Industries}

(FLORIDA, 2011). Como já ressaltado, as "cidades criativas" vão mais além de um local economicamente vantajoso, são espaços que revelam um passado único. A cultura neste espaço deverá ser a base da criatividade e não a barreira à mesma. A visão de que a cultura não traz benefícios econômicos se revela limitada, em especial na atualidade, onde é possivel elencar possibilidades de se gerar renda por meio da cultura sem que se perca a essência cultural.

A cultura local quando preservada e difundida é uma vantagem economicamente sustentável, é a valorização da história local, que por si gera e atrai uma diversidade de outras atividades. Neste contexto não é aconselhável copiar modelos de sucesso ocorridos em outros lugares. Em um meio em que a singularidade é uma das características principais e a própria razão do sucesso destes lugares, a existência de modelos preestabelecidos que possam ser seguidos como um guia de cidades não parece ser o processo mais adequado, quando o que se pretende é a originalidade e a unicidade dos locais (REIS, 2012). Para criar estratégias de desenvolvimento e estímulo de cidades criativas é necessário respeitar os traços característicos de cada região, as tradições e costumes dos territórios que compõem a cidade ou localidade (EMMMENDOERFER; FIORAVANTE; ARAÚJO, 2018).

Simas (2009) também propõe a originalidade dos modelos para cada local. Segundo esta autora, o desafio das regiões, sociedades e cidades futuras será saber gerar uma competitividade regional, através de um desenvolvimento de base localmente sustentável, que seja capaz de realçar e também de valorizar toda a identidade local, transformando-a em uma oportunidade, uma "vantagem absoluta" e uma garantia de independência pela diferenciação. 0 crescimento deverá derivar de soluções personalizadas e adaptadas pelos diferentes atores regionais, apenas deste modo serão aceites por todos e poderão ser transmitidas (SIMAS, 2009).

Landry e Bianchini (1995) apresentam argumentos que justificam a importância de se enxergar a criatividade como elemento essencial para a formação e desenvolvimento das cidades. Segundo os autores, as cidades sempre precisaram de criatividade para funcionar como mercados, centros comerciais e de produção, com sua massa crítica de empresários, artistas, intelectuais, estudantes, administradores e corretores de poder (LANDRY; BIANCHINI, 1995).

Sendo assim, observa-se a relação direta entre criatividade/inovação e as cidades criativas, em que as bases para inovação estão na criatividade, e estas em conjunto são condições necessárias, mas não suficientes para a construção de espaços urbanos mais criativos. Não são suficientes porque, como 


\section{Brazilian \\ Creative Industries}

ressalta Reis (2012), uma cidade criativa está alicerçada sobre um tripé, que é formado além da inovação pelas conexões e pela cultura.

\subsection{A TRÍADE NA CIDADE CRIATIVA: CONEXÕES, CULTURA E INOVAÇÃO}

Em uma cidade criativa, independente do seu porte, da sua história, de suas questões socioeconômicas, segundo Reis e Urani (2011), há uma prevalência de três elementos, os quais constituem a base de formação de um espaço urbano, em constante mutação.

O primeiro elemento remete às inovações, que não devem ser vistas apenas na visão das inovações tecnológicas, como apontado por Florida (2011), mas são entendidas também como a criatividade aplicada à solução de problemas ou à antecipação de oportunidades. São as conexões que viabilizam uma série de ligações, entre pessoas e seus espaços, entre os seus habitantes e seus governos, o que está profundamente ligado à identidade e à essência da cidade, bem como ao entendimento do passado para construir o futuro (REIS, 2012). Embora a associação mais recorrente ao termo seja referente às inovações tecnológicas, a criatividade urbana é sustentada por inovações das mais diversas ordens, como sociais, culturais, institucionais e ambientais.

A respeito da relação entre criatividade e inovação, Landry e Bianchini (1995) destacam um aspecto importante:

\footnotetext{
Uma cidade pode ser criativa, mas pode não ter habilidades analíticas, avaliativas e financeiras para desenvolver soluções inovativas. A criatividade é uma pré-condição necessária para haver inovação, mas a inovação é o que conta para maximizar o potencial de uma cidade. Atingir a criatividade a partir da inovação envolve a avaliação. 0 processo de avaliação envolve avaliar o quão apropriada uma idéia é para uma determinada situação, sua viabilidade, a relação custo-eficácia e popularidade. Algumas cidades podem se especializar em criatividade e outras em inovações (LANDRY; BIANCHINI, 1995, p. 24, tradução nossa).
}

As conexões, segundo Reis e Urani (2011), são o segundo elemento na constituição de cidades criativas e podem se manifestar em diferentes dimensões, como: a) histórica, que envolve os aspectos do passado da cidade, que forma sua identidade e sua estratégia de futuro, desenhando a cidade que se quer ter; b) geográfica, entre bairros e zonas, o que é especialmente importante nas grandes cidades, não raro fragmentadas; de governança, com a participação dos setores público, privado e da sociedade civil, cada um com seu papel muito claramente definido; c) diversidades, aglutinando pessoas com distintos pontos de vista, profissões, culturas, comportamentos; d) entre local e global (glocalização), preservando as singularidades da cidade, sem por isso se isolar ou de desconectar do mundo. 


\section{Brazilian \\ Creative Industries}

Ainda, assume-se que a cultura é um ativo de enorme valor para uma cidade criativa, por seus benefícios culturais, mas também pelos impactos sociais e econômicos que desencadeia, pelo reconhecimento de que agrega valor e aumenta a competitividade de setores tradicionais da economia e como fonte de inspiração. A cultura e a criatividade são as alavancas para tornar possível uma cidade criativa, e uma vez ausentes acabam impossibilitando a prosperidade das regiões (SIMAS, 2009).

No contexto de uma cidade criativa, como terceiro elemento, a cultura confere a singularidade do espaço, como se fosse a sua marca registrada. Segundo Reis (2012), a cultura se insere na cidade criativa sob quatro formas mais visíveis:

1. Por seu conteúdo cultural per se, compreendendo produtos, serviços, patrimônio (material e imaterial) e manifestações de caráter único;

2. Por meio das indústrias criativas, abrangendo cadeias culturais, da criação à produção, do consumo ao acesso, com impacto econômico na geração de emprego, renda e arrecadação tributária;

3. Pela agregação de valor a setores tradicionais, conferindo a estes diferenciação e unicidade, em um contexto mais amplo de economia criativa;

4. Por ser capaz de formar um ambiente criativo, pela convivência de diversidades e manifestações, fonte de inspiração para olhares e ideias diferentes, em especial pelas artes.

Em relação a estas quatro formas, dados dos últimos anos evidenciam que cultura e criatividade passaram a representar um setor econômico significativo, responsável por 5,4\% do emprego global (ISERNIA; LAMONICA, 2021). As atividades produtivas inseridas na economia criativa criam novas oportunidades de trabalho, de bens e serviços inovadores, bem como auxiliam na geração de novas competências para um trabalho digno e inclusivo, com produção e consumo mais sustentáveis.

De acordo com o Relatório da Conferência das Nações Unidas sobre Comércio e Desenvolvimento (UNCTAD), publicado em 2019, o mercado global de produtos da Economia Criativa saltou de US\$208 bilhões em 2002 para US\$ 509 bilhões em 2015. No contexto brasileiro, juntos, os subsetores que compõem a Economia Criativa movimentam R $\$ 171,5$ bilhões por ano, o equivalente a $2,64 \%$ de toda a riqueza nacional (FIRJAN, 2019). O Sistema de Informações e Indicadores Culturais do IBGE registrou, em 2018, a existência de 5,2 milhões de pessoas ocupadas em atividades culturais e criativas no Brasil (SIIC/ IBGE, 2019). Em 2016, os estados que mais concentravam empregos formais da economia criativa eram São Paulo, Rio de Janeiro e Minas Gerais.

Tendo por base estes três elementos essenciais, a cidade criativa pode ser vista como em constante processo de modificação, como apresenta Reis (2012), é uma cidade que tem uma cultura própria, com abundância de inovações e múltiplas conexões. O sentido de ser uma cidade criativa perpassa então pela 


\section{Brazilian \\ Creative Industries}

noção de um espaço que se norteia por algo tão intangível como a criatividade, e que é, portanto, uma cidade dinâmica, e que possui um sentido de mudança próprio.

\subsection{O QUE SIGNIFICA SER UMA CIDADE CRIATIVA?}

Esta pergunta estimula a refletir sobre alguns pontos: primeiro, porque a criatividade tem ganhado tanto destaque nos últimos tempos, e, em especial, para as cidades? Segundo, porque estimular a criatividade é importante para alcançar o desenvolvimento econômico?

Estas questões trabalhadas por Landry e Bianchini (1995) ganharam na atualidade uma abrangência de discussões e têm sido reconhecidas pelos diversos atores da sociedade, tendo sido rapidamente incorporadas no discurso e nas prioridades das agendas políticas para o desenvolvimento (CRUZ, 2010). A UNCTAD e a UNESCO têm contribuído para fortalecer o debate em torno destes temas globalmente, assumindo a visão de que utilizar cultura e criatividade em diferentes facetas da governança urbana é a força motriz para promover o desenvolvimento sustentável.

A Rede de Cidades Criativas da UNESCO hoje é composta por 246 cidades de mais de 80 Estadosmembros da UNESCO, em sete áreas criativas: artesanato e arte folclórica, design, cinema, gastronomia, literatura, mídia e música (ASHTON, 2018). Para Landry e Bianchini (1995) uma cidade criativa pode ser entendida como o espaço que estimula e incorpora uma cultura de criatividade no modo como os stakeholders urbanos atuam.

Ser uma "cidade criativa" implica em alguns traços característicos como a valorização dos recursos culturais (como a diversidade), o estabelecimento de correlação entre os recursos culturais e potencial de desenvolvimento econômico, políticas públicas transdisciplinares e transversais (REIS, 2008); maior participação cidadã, existência de incentivos à criatividade, capazes de proporcionar a existência de uma estrutura criativa que promovam a efervescência de ideais, manifestações e busca por soluções criativas para a sociedade em geral.

Neste sentido, é estratégico estimular novos talentos e mentes criativas, mas também ser capaz de atraí-los e mantê-los (LANDRY; BIANCHINI, 1995), pois os trabalhadores criativos são, segundo Florida (2011), desejados pelas cidades, o que acaba proporcionando a criação de ambientes propícios à atração e à manutenção destes profissionais. Mas essa classe criativa (FLORIDA, 2011), que seria, portanto, fundamental para garantir a competitividade das cidades (REIS, 2012), depende de alguns aspectos essenciais para florescer. A classe criativa de Florida (2011), que movimenta e ajuda a construir uma cidade criativa, depende:

De uma administração pública que tenha imaginação [e visão], onde haja inovações 


\section{Brazilian \\ Creative Industries}

sociais, criatividade [...] e política e governança. [...] criativos não são apenas os artistas ou os que trabalham com novas mídias, design e pesquisas em universidades. A questão central é: quais são os atributos especiais que os artistas, a economia criativa e a classe criativa podem oferecer para fazer uma cidade mais criativa (LANDRY, 2013, tradução nossa e grifo nosso).

Na "Creative Cities Structured Policy Dialogue Backgrounder", Bradford (2004) propõe pontos relevantes que podem caracterizar tanto a estrutura de uma cidade criativa quanto as suas funções. $O$ autor deixa claro em sua obra a diferença entre cidades comuns e criativas.

As cidades criativas são locais dinâmicos de experimentação e inovação, onde novas
ideias florescem e pessoas de todos os tipos e esferas da sociedade estão juntas para
tornar suas comunidades um lugar melhor para viver, trabalhar [...]. São lugares que
encorajam diferentes tipos de conhecimento e encorajam uma ampla participação
pública para lidar criativamente com questões complexas [...] enquanto todas as
cidades são caracterizadas pela densidade populacional e pela sua proximidade
organizacional, apenas nas cidades criativas essas características se tornam ativos em
esforços de colaboração para resolver os problemas urbanos que são perenes, como
congestionamentos, moradia, inclusão [...] (BENDFORD, 2004, p. 1, tradução nossa).

Assim, a criatividade é importante para as cidades frente ao processo de globalização, ajudando a promover desenvolvimento mais sustentável (BRADFORD, 2004). No processo de globalização, pesquisadores rastream convergências de fluxos de urbanização - de pessoas, investimentos e ideias que tornam as cidades mais importantes para o bem-estar social.

Reis e Urani (2011) também propõem reflexões acerca do significado de "ser uma cidade criativa" e de quais são as condições de base deste lugar, perpassando por conceitos apresentados por Florida (2011), onde a cidade criativa é aquela que apresenta uma maior concentração da "classe criativa" em seu território. É um tanto estranho que para que uma cidade seja bem sucedida criativamente, ela deva olhar para fora, para as conexões externas, atraindo pessoas que se enquadrariam na classificação de classe criativa, e não em um processo endógeno, para dentro, estimulando a criatividade de seus habitantes, independentemente da profissão que estas exerçam (REIS; URANI, 2011).

Por outro lado, ao invés de privilegiar a presença de uma classe criativa, de um grupo de pessoas no seio urbano, a cidade criativa é sistêmica, integrada e incentiva a eclosão da criatividade de todas as profissões, de forma complementar. Assim, a dinâmica é: a cidade, por apresentar uma esfera que favorece colocar o exercício da criatividade em prática e por ter aspectos culturais, econômicos, sociais e institucionais que favorecem esse exercício, irá atrair o talento criativo e as indústrias criativas, acontecendo 


\section{Brazilian

retroalimentação do espaço urbano, em que mais talento torna o espaço mais criativo, o que atrai novos talentos, e assim segue o fluxo (HIRSCHMAN, 1961).

Apesar de autores como Florida (2011) trabalharem com foco em grandes metrópoles, pequenos espaços urbanos podem ser inovadores e capazes de estimular inspirações que promovem redes urbanas e/ou rurais, em termos culturais e socioeconômicos, em diferentes escalas territoriais (EMMENDOERFER; ASHTON, 2014). A cidade criativa não é delimitada em função de sua grandeza geográfica ou populacional, não é condicionada apenas por aspectos físicos, uma cidade criativa é uma cidade que surpreende, que inclui, que inova, transcende a materialidade, que valoriza a cultura, questiona e dá espaço para todas as vozes e pensamentos alternativos na busca constante por soluções para alcançar o desenvolvimento sustentável.

\section{RESULTADOS E DISCUSSÃO}

Neste tópico serão apresentadas sucintamente as discussões baseadas nos dados encontrados na cidade de Ouro Preto. Inicialmente é necessário fazer uma breve caracterização da unidade de análise deste estudo, apresentando suas características históricas, culturais, espaço-urbanísticas e criativas. Em sequência, são apresentados dois tópicos que tratam da análise dos dados coletados na pesquisa de campo. Esses foram divididos em dois blocos que subdividem cada um, em categorias. 0 primeiro bloco trata das motivações e preferências dos entrevistados e o segundo, das frustações e fatores críticos observados. Por fim, encerra-se a discussão dos resultados com uma breve reflexão sobre o potencial criativo da cidade de Ouro Preto.

\subsection{A CIDADE EM ESTUDO}

Ouro Preto foi a primeira cidade brasileira a receber o título de Patrimônio Cultural da Humanidade, em 1980, por seu singular valor histórico. Por essa razão, recebe diariamente um fluxo intenso de turistas, vindos de toda parte do mundo, que desejam, entre vários outros motivos, conhecer sua história, paisagens, gastronomia, dentre outros inúmeros atrativos. Sua população (cerca de 70 mil habitantes) é bastante diversificada e composta por descendentes de várias regiões do país, de portugueses e de escravos, além de outras nacionalidades minoritárias que foram atraídas pelo ouro do período colonial.

Mais recentemente, tem sido também formada pela comunidade universitária, presente desde a fundação da Escola de Farmácia, em 1839, e da Escola de Minas, em 1876, hoje incorporadas à Universidade Federal de Ouro Preto - UFOP, além disso, contam-se também artistas e intelectuais, 


\section{Brazilian \\ Creative Industries}

atraídos para a cidade após ser redescoberta pelos modernistas em 1924, e um grande contingente de turistas (GRAMMONT, 2006).

Com todo esse arcabouço, a cidade tem se destacado como berço cultural e abriga diversas culturas que se misturam e se integram, formando novos conceitos de arte e cultura, ao mesmo tempo em que mantém preservadas suas tradições e sua riqueza histórica e patrimonial. Possui ainda uma programação de eventos ao longo do ano, voltados para diversos públicos, sendo que os eventos culturais de maior destaque atualmente são: o Carnaval, o Festival de Inverno de Ouro Preto e Mariana - Fórum das Artes, a Semana Santa, o Aniversário da Cidade, a Festa do 12 e o Festival Internacional "Tudo é Jazz", o que proporciona aos grupos de teatro locais grandes oportunidades de atuação e interação (SANDOVAL; ARRUDA; SANTOS, 2009).

Percebe-se neste aspecto a importância da dimensão cultural na cidade. A base cultural de Ouro Preto cria uma singularidade entre demais espaços urbanos do país, principalmente por conta de sua história, dos produtos, serviços, patrimônio (material e imaterial) e manifestações (REIS, 2012; REIS; URANI, 2011) de caráter único presentes na cidade. Ainda, a oferta cultural encontrada na cidade configura um fator importante de atração de pessoas, turistas, pesquisadores, intelectuais e profissionais ligados a diversos segmentos que têm a criatividade como fonte de insumo principal (HALL, 2000).

A cidade pode ser vista como um espaço constante de interação entre pessoas de diferentes etnias, pensamentos e saberes, criando uma atmosfera de tolerância (FLORIDA, 2011). A presença de universidades, centros de pesquisas e empresas de grande porte, em um contexto carregado de expressões culturais, que abriga diferentes segmentos criativos, como as artes, o patrimônio, música, software, dentre outros, acaba proporcionando a formação de um ambiente propício ao exercício da criatividade e da inovação (FLORIDA, 2011; REIS; URANI, 2011; LANDRY; BIACHINI, 1995).

Quanto às suas características urbanísticas, Ouro Preto é reconhecida como modelo de espaço urbano e arquitetura da ocupação do interior do país no período colonial, caracterizada pelo somatório de arruamentos, edificações e equipamentos urbanos dos séculos XVIII, XIX e XX. Em relação ao núcleo urbano surgido e erguido durante o período colonial, o sítio natural e as características da atividade mineradora condicionaram o traço característico do seu desenho urbano. A partir de 1945, tem início um grande crescimento populacional na cidade. O núcleo urbano principal, que se mantinha praticamente inalterado desde os fins do século XVIII, sofre um processo de expansão, sendo aproveitadas todas as áreas da periferia que oferecem condições razoáveis.

Para Sobreira e Fonseca (2001), a necessidade de criação de novas áreas urbanas em função do crescimento da população, a partir dos anos 60, não foi acompanhada por planejamento prévio adequado, levando à ocupação de áreas onde se desenvolveram atividades de mineração no passado. Por essa 


\section{Brazilian \\ Creative Industries}

descrição preliminar do espaço urbanístico, pode-se observar a existência de problemas de conexão em Ouro Preto. A cidade convive com problemas de mobilidade intraurbanas, como o transporte, e extraurbanas, como a atividade turística que revela conexões com a cidade principalmente pelos equipamentos culturais e pela oferta cultural, que atrai turistas domésticos e internacionais (EMMENDOERFER, 2019).

\subsection{MOTIVAÇÕES E PREFERÊNCIAS}

No questionário foram elaboradas perguntas que tratavam do poder de atração da cidade, o que motivava tantas pessoas dos mais diversos lugares a visitar a cidade, a conhecer seu patrimônio, suas artes e manifestações culturais. 0 conjunto de respostas que formam este bloco originou um conjunto de quatro subcategorias de análise. Sendo assim, no critério motivações e preferências foram encontradas as subcategorias: a) Patrimônio cultural, arquitetura e equipamentos culturais; b) Artesanato, artes e manifestações culturais; c) Atividades de pesquisa, difusão de conhecimento e desenvolvimento; d) Meio ambiente.

A existência de um conjunto arquitetônico barroco, formado por casarios, igrejas, monumentos, teatros, dentre outros ativos e equipamentos culturais, confere à cidade de Ouro Preto uma singularidade, uma identidade que a torna reconhecida internacionalmente. A cidade, berço da cultura de Minas Gerais, é carregada de conteúdos simbólico e do patrimônio intangível, o que alimenta o quesito cultura, um dos três eixos estruturantes da "cidade criativa", além disso, motiva a atração de turistas (REIS, 2011; SIMAS, 2009; HALL, 2000).

A oferta cultural enquanto estímulo à mobilidade fica evidente nas falas de alguns entrevistados quando foram perguntados sobre as motivações para o turismo: "conhecer a arquitetura, as igrejas e os casarios (E17)". "Pela riqueza histórica e o patrimônio (E5)". "As ruas e o conjunto arquitetônico, especificamente a cidade colonial, suas estruturas e o aspecto cinematográfico que a cidade apresenta (E54)". Somam-se a isso os equipamentos culturais como museus, teatros e bibliotecas, enquanto elementos importantes do quesito cultura na cidade (REIS, 2011).

No quesito inovações, outro importante eixo estruturante de uma cidade criativa, Ouro Preto revela atividades de pesquisa, difusão de conhecimento e desenvolvimento. Em se tratando de educação, além de sediar o campus de uma universidade e de faculdades, de institutos de pesquisa, a cidade tem atraído constantemente pesquisadores, historiadores e intelectuais, que enxergam a cidade como um lócus potencial para estudo. Soma-se a isso o acontecimento constante de eventos e congressos, espaços para a fruição do saber e estimulantes da criatividade.

A cidade concentra também diversos segmentos pertencentes ao campo da economia criativa, como o das artes cênicas, com os grupos de teatro, das artes visuais, expressões culturais, design e entre 


\section{Brazilian \\ Creative Industries}

outros, o que contribui para o exercício da criatividade, além, é claro, da geração de emprego e renda na cidade (FLORIDA, 2011; REIS; URANI, 2011; LANDRY; BIACHINI, 1995). As falas dos entrevistados ilustram aspectos do quesito inovação: "Me motiva vir aqui, o interesse pela história e por motivos de execução de uma pesquisa em arquivos (E11)". "A cidade possui uma arquitetura rica, artesanato e gastronomia característicos (E19)". "O que me trouxe aqui foi a ocorrência de um evento na cidade (E50)". "As joias, as pedras preciosas, que são produzidas aqui, são o motivo da visitação (E4)".

\subsection{FRUSTAÇÕES E FATORES CRÍTICOS}

O questionário abordava, ainda, sobre os gargalos encontrados na cidade pelos visitantes, que se traduziam em fatores críticos de mobilidade, planejamento urbano e organização. Estes acabam provocando frustações aos visitantes da cidade e mesmo para os seus residentes. 0 conjunto de respostas que formam este bloco deu origem a cinco subcategorias de análise: a) Mobilidade; b) Planejamento urbano; c) Programação e organização dos atrativos turísticos; d) Capacitação para o turismo; e) Conservação do Patrimônio; f) aqueles que não tinham nada a declarar.

As primeira subcategorias representam problemas de gestão urbana relacionados à conexão da cidade e à péssima condição do trânsito, que dificulta a locomoção dentro do centro histórico e entre o entorno do município. 0 entrevistado E25 relata "a inexistência de transporte direto entre Ouro PretoTiradentes e outras localidades". Outro entrevistado diz: "A cidade não comporta o tráfego intenso, o trânsito, a falta de estacionamentos são fatores críticos" (E57).

A carência de transportes para o entorno da cidade revela um problema de conexão interurbana, mas que causa também um problema de conexão extra-urbana (REIS, 2011). Além dos problemas de mobilidade e locomoção, elementos também de infraestrutura urbana, na cidade, é percebido ainda os problemas de falhas, ou até mesmo ausência, das conexões extra-urbanas, que foi identificado principalmente nas respostas daqueles entrevistados que ressaltavam como fatores críticos da cidade os problemas relacionados à programação e organização dos atrativos turísticos e à capacitação para o turismo. As falhas de conexão extra-urbanas estão diretamente ligadas à dinâmica do setor do turismo, aos problemas do assédio de guias, à falta de informação na cidade, à agenda de horário de funcionamento dos atrativos turísticos e à baixa qualidade e preparo do comércio local.

O entrevistado E30 aponta: "Há falta de informação, temos dificuldades na identificação dos locais. Deveria ter um ponto visivel de informação, como um ponto turístico central para atendimento". Além disso, "a locomoção na cidade é um fator crítico, principalmente por causa da idade avançada, e os guias não são capacitados para a visitação (E34)". Somado a tudo isto, acrescentam-se "os aspectos negativos de infraestrutura da cidade, como locomoção, falta de sinalização e limpeza (E45)". 


\section{Brazilian \\ Creative Industries}

Problemas de infraestrutura urbana afetam em longo prazo os aspectos de conexão com o resto do mundo. Como a cidade é reconhecida internacionalmente, a imagem da cidade pode afetar o nivel de investimentos internacionais no país (REIS, 2011). Identificou-se também a falta de conexões entre os agentes públicos e os demais atores na cidade, revelando a ausência de governança. Pode-se identificar, na cidade, uma baixa articulação entre o setor público e privado e entre as esferas públicas municipal, estadual e federal.

\section{DESAFIOS PARA AS CIDADES CRIATIVAS EM CONTEXTO PÓS-PANDÊMICO}

Entre tantas mudanças consequentes da pandemia da Covid 19, destaca-se o impacto sofrido pelas cidades. Estas experimentaram o esvaziamento de suas ruas, restrições da vida urbana e da participação dos indivíduos em atividades culturais. A atividade turística cessou, a economia foi se deteriorando e as desigualdades aumentaram dentro de um curto espaço de tempo. Neste contexto, o aumento das desigualdades - social, humana, econômica, educacional - é um dos maiores desafios impostos para as cidades criativas ou aquelas que querem se tornar criativas, em especial, quando se trata de países emergentes (ISERNIA; LAMONICA, 2021), como é o caso do Brasil.

Por outro lado, observa-se o fortalecimento da importância do lugar e de se criar uma identidade local, o estreitamento das relações com o espaço onde se habita e uma visão mais orgânica em torno de tudo o que acontece no território. Grande parte das dificuldades e dos problemas urbanos não são novos, mas estes problemas ficaram mais explícitos com a pandemia da Covid-19, não havendo mais espaço para manter uma visão descolada da realidade. Por isso, a pandemia trouxe para as cidades o desafio de repensar formatos e soluções inovadoras e criativas que promovam a recuperação da qualidade de vida dos indivíduos, das condições de trabalho e colabore para aumentar a inclusão social.

Para superar o desafio das desigualdades, entre outras mudanças, é importante inovar na forma de se consduzir as políticas para recuperação e requalificação de lugares (placemaking), estabelecendo articulações para cocriar soluções via parcerias público-privadas e outros setores da sociedade no intuito de melhorar os indicadores sociais, os niveis de renda e emprego e por consequência de bem-estar. É importante observar ainda como ocorrerá a evolução da pandemia (e a eminência de novas crises de natureza semelhante), os avanços no processo de digitalização e a evolução nos mecanismos de cooperação, fortalecendo cada vez mais uma estrutura de governança.

Os setores culturias e criativos estão entre os mais afetados, tendo em vista a adoção de medidas para restringir a mobilidade individual e para implementar o distanciamento social, o que reduziu significativamente $o$ acesso à cultura em todas as suas formas, especialmente a partir do fechamento 


\section{Brazilian \\ Creative Industries}

de equipamentos culturais, de bens do Patrimônio Mundial e instituições culturais, elementos estes importantes para uma cidade criativa, como é o caso da cidade de Ouro Preto. Entre os setores culturais e criativos mais afetados e que demonstram grande representatividade na cidade de Ouro Preto estão os relacionados ao turismo cultural, museus e artes, isso sem considerar a economia informal que (sobre)vive da cultura e do turismo no local. Toda a cadeia de valor criativo (criação, produção, distribuiçãa e acesso) tem sido afetada. Quando se analisa o impacto na classe criativa atuante para estes setores, observase enfraquecimento significativo, em termos de posição social e econômica de artistas e profissionais culturais.

Tendo em vista os elementos inovações, conexões e cultura, apontados neste trabalho como essenciais para constituir uma cidade criativa, a pandemia não os enfraquece quanto a suas validades e importância. Os desafios impostos pelo contexto atual vão requerer esforços conjuntos entre o setor público, privado e sociedade civil organizada que trabalhem estratégias em diversas frentes, em especial quando se trata das "conexões", revelando-se o elemento que mais foi impactado.

As conexões assumiram uma forma virtual (remota), no entanto, é algo muito diferente da vida urbana cotidiana pré-pandêmica, quando os indivíduos estabeleciam as suas conexões ocupando os espaços públicos. O desafio da reinvenção na sociedade (pós)pandêmica está em elaborar estratégias que permitam reestabelecer estas conexões com a mesma vitalidade do modo anterior.

Em relação às inovações, o desafio para as cidades está em desenhar e implementar políticas, programas e projetos de apoio à cultura, pesquisa e formação, com o objetivo deestimular a economia criativa da cidade, sendo assim capaz de reconhecer a criatividade como motor de mudança e desenvolvimento sustentável (UNESCO, 2020). Somado a isso, as pessoas estão sendo desafiadas a reequilibrarem a vida on-line e off-line. Este ponto é válido tanto para aspectos profissionais e econômicos quanto para as relações pessoais. A capacidade de fortalecer as inovações implica diretamente no fortalecimento das conexões entre os diferentes stakeholders e territórios que podem formar uma cidade.

Do ponto de vista da economia criativa e da cultura, as cidades que conseguirem estruturar uma política focada no digital que permita a retomada segura da oferta de bens e serviços culturais e criativos podem ter mais capacidade de atrair e reter diferentes riquezas (MENDONÇA; COVAS, 2020). Será necessário que as cidades fortaleçam a criatividade e as indústrias culturais e criativas, promovendo-as através de um plano de desenvolvimento local com cooperação nacional e internacional (REIS, 2012), proporcionando oportunidades de transferência de conhecimentos (FLORIDA, 2011).

Quanto aos aspectos culturais, entre os desafios está o de implementar projetos que busquem transformar a cidade por meio de valores culturais e incentivar a cooperação de todas as partes 


\section{Brazilian

interessadas para promover interações nacionais e internacionais. Neste sentido, é necessário procurar modernizar a infraestrutura urbana em harmonia com a cultura local.

Em relação aos Objetivos de Desenvolvimento Sustentável (ODS) da ONU, pode-se identificar pelo menos 8 ODS que devem ser tratados como prioritários por meio de políticas e projetos para que as cidades se tornem mais criativas:

- ODS 3 - Boa saúde e bem-estar;

- ODS 4 - Educação de qualidade;

- ODS 8 - Trabalho decente e crescimento econômico;

- ODS 9 - Indústria, Inovação e Infraestrutura;

- ODS 10 - Redução das desigualdades;

- ODS 11 - Cidades e Comunidades Sustentáveis;

- ODS 17 - Parcerias e meios de implementação;

- ODS Emergente - Ações contra mudanças climáticas.

Neste sentido, laboratórios para inovação (EMMENDOERFER, 2020) no setor público podem ser espaços de fomento à participação social e solidariedade, bem como de práticas de placemaking criativo. Ações como essas podem empoderar as pessoas e, por consequência, as cidades como criativas e mais próximas do que se espera em termos de sustentabilidade (EMMENDOERFER et al., 2020) em uma sociedade pós-pandêmica, envolvendo expressões de resiliência, inclusão, equidade e preservação de saberes tradicionais na sociedade.

Assim, as reflexões sobre as cidades criativas em contexto pós-pandemia destacam a importância de que não bastará investir apenas no desenvolvimento de uma economia criativa, será necessário considerar esta questão de forma plural e intersetorial. É necessário que se organize arranjos institucionais de governança que permitam implementar inovações para a solução dos mais diversos problemas urbanos recentes, inclusive como políticas públicas (EMMENDOERFER, 2019) de desenvolvimento local ou para territórios que compõem a cidade.

\section{CONSIDERAÇÕES FINAIS}

Observou-se, com este estudo, que na cidade de Ouro Preto existem limitações de conexões justamente onde é possível encontrar criatividade e cultura e espaço para inovação, apesar deste pilar ainda estar em processo de fortalecimento. $O$ tripé formador de uma cidade criativa fica assim incompleto. Há carência de projetos culturais transversais a todos os setores e falta inovação, não apenas tecnológica, 


\section{Brazilian

mas para lidar com problemas como os sociais e de infraestrutura urbana, a fim de tornar esta cidade um espaço mais propício à imaginação, à criatividade e ao turismo sustentável.

A partir deste estudo, verificou-se que para uma cidade ser criativa é necessário fortalecer determinados aspectos. A cultura, sendo um dos elementos integrantes do tripé que forma e sustenta uma cidade tem uma presença marcante. A presença de equipamentos culturais, de produtos, serviços, patrimônio (material e imaterial) e manifestações de caráter único que além de tudo promovem um impacto econômico na geração de emprego, renda arrecadação tributária, confere uma diferenciação e unicidade à cidade. Porém, a cidade carece de melhor conservação de seu patrimônio e melhorias em seus equipamentos culturais, melhor organização do seu setor de serviços, melhor capacitação daqueles que apresentam a cultura e história da cidade para os visitantes.

As conexões são o ponto mais frágil da cidade. Identifica-se a necessidade de fortalecimento das conexões intraurbanas, levando ao uma menor fragmentação do espaço urbano; fortalecer as conexões com a região do entorno, com o mundo e entre o público e o privado; fortalecer as conexões entre o intangivel e o tangivel; enfim, fortalecer as múltiplas conexões que sustentam uma cidade criativa. Vale ressaltar que há também a necessidade de fortalecimento da cultura de inovações. As inovações que devem ser entendidas desde aquelas que emanam de pesquisas e envolvem tecnologias, até as inovações sociais, que buscam a solução para problemas renitentes ao espaço urbano por meio do exercício da criatividade.

Por fim, pode-se ressaltar o fato de que o tema economia criativa e as infinitas possibilidades de aplicação do insumo criatividade em iniciativas pró-desenvolvimento são recentes, pois apenas em 2005 é que o tema ganha discussões mais ampliadas, mesmo assim, há lacunas de informações, gestão de conhecimento e a incipiência de um corpo consolidado de teorias e estudos aplicados para o Brasil. Somase a isso a carência de eventos que estimulem reflexões e discussões sobre o tema, bem como suas possibilidades de aplicação. Há ainda a limitada oferta de capacitações e ações de gestão de conhecimento nesta área, principalmente para gestores públicos e atores estratégicos para o desenvolvimento de cidade criativas.

\section{AGRADECIMENTOS}

AoConselho Nacional de Desenvolvimento Científico e Tecnológico (CNPq - Processos 309363/20195), à Fundação de Pesquisa de Minas Gerais (FAPEMIG - Processos APQ-01870-15; PPM-00049-18) e à Coordenação para o Aperfeiçoamento de Pessoal de Nível Superior (CAPES - Financiamento 001), 


\section{Brazilian Creative Industries}

Brasil. Agradecimentos adicionais à equipe editorial pelas suas valiosas contribuições que repercutiram positivamente no presente artigo.

\section{REFERÊNCIAS}

ASHTON, M. S. G. Cidades criativas: contexto histórico e conceitual. In: ASHTON, Mary Sandra G. (Org.).

Cidades criativas: vocação e desenvolvimento. Novo Hamburgo: Editora Feevale, 2018, p. 13-30. Disponivel em: https:/www.feevale.br/Comum/midias/b8f7d75d-202c-48ab-9330-6b941321df51/E-B00K\%20Cidades\%20Criativas.pdf. Acesso em: 31 abr. 2021.

BARDIN, L. Análise de conteúdo. Lisboa: Edições 70, 2015.

BRADFORD, N. Creative cities structured policy dialogue backgrounder. Ottawa: Canadian Policy Research Networks, 2004. Disponivel em: http://www.cprn.org/documents/31340_en.pdf. Acesso em: 12 abr. 2021.

BRITISH COUNCIL. Mapping the creative industries. London: the UK context, 2005.

CANCLINI, N. G. ¿ Síntomas o conflictos? Políticas e investigaciones urbanas. Alteridades, v. 18, n. 36, p. 13-22, 2008.

CAVES, R. Creative Industries. Cambridge, Mass: Harvard: Harvard University Press, 2000.

CRUZ, A. R. P. M. Turismo e Criatividade no Algarve: uma análise da oferta turística regional como elemento de atração da classe criativa. 2010. Dissertação (Mestrado em Turismo) - Universidade do Algarve, Faro, Portugal, 2010.

EMMENDOERFER, M. L.; ASHTON, M. S. G. Territórios Criativos e suas Relações com o Turismo. Revista Turismo \& Desenvolvimento, n. 21, p. 459-468, 2014. On-line. Disponível em: <https://edisciplinas.usp. br/mod/resource/view.php?id=3236314 . Acesso em: 28 jan. 2021.

EMMENDOERFER, M. L.; FIORAVANTE, A. S. A.; ARAÚJO, J. F. F. E. Federal government actions for the creative territories development in Brazilian context. Revista Brasileira de Gestão e Desenvolvimento Regional, v. 14, n.1, p.400-424, 2018. Disponivel em: https://www.rbgdr.net/revista/index.php/rbgdr/ article/download/3497/654. Acesso em: 28 abr. 2021.

EMMENDOERFER, M. L. Creative tourist regions as a basis for public policy. In: DUXBURY, Nancy; RICHARDS, Greg. (Eds.). A Research Agenda for Creative Tourism. Cheltenham, UK: Edward Elgar Publishing, 2019. pp. 151-166. 


\section{Brazilian \\ Creative Industries}

EMMENDOERFER, M. L. Movimento de laboratórios para inovação como lócus de solidariedade democrática e de enfrentamento à pandemia COVID-19. NAU Social, v. 11, n. 21, p. 413-426, 2020.

EMMENDOERFER, M. L.; MEDIOTTE, E. J.; VASCONCELOS, C. A. S.; VITÓRIA, J. R.; PAULA NETO, A. Placemaking como vetor de desenvolvimento em uma sociedade pós-pandemia. DELOS: desarrollo local sostenible, v. 13, n. 37, p. 1-23, 2020. DOI: https://doi.org/10.5281/zenodo.4553310.

EVANS, G. Hard branding the cultural city-from Prado to Prada. International journal of urban and regional research, v. 27, n. 2, p. 417-440, 2003.

FIRJAN. Mapeamento das indústrias criativas. Rio de Janeiro: FIRJAN, 2019. Disponivel em: https:// www.firjan.com.br/EconomiaCriativa/downloads/MapeamentolndustriaCriativa.pdf. Acesso em: 13 maio 2021.

FLORIDA, R. A ascensão da classe criativa. Porto Alegre: L\&PM, 2011.

GODOI, C. K.; MATTOS, P. L. C. L. Entrevista qualitativa: instrumento de pesquisa e evento dialógico. In: SILVA, A. B.; GODOI, C. K.; BANDEIRA-DE-MELO, R. (orgs.). Pesquisa qualitativa em estudos organizacionais: paradigmas, estratégias e métodos. 2. ed. São Paulo, 2010. p. 301-323.

GRAMMONT, A. M. Ouro Preto: problemas de um patrimônio histórico no início do século XXI. Turismo-Visão e Ação, v. 8, n. 3, p. 455-467, 2006.

HALL, P. Creative cities and economic development. Urban Studies, v. 37, n. 4, p. 639-649, 2000.

HARTLEY, J. Creative Industries. London: Blackwell, 2005.

HIRSCHMAN, A. O. Estratégia do desenvolvimento econômico. Rio de Janeiro: Fundo de Cultura, 1961.

HOWKINS, J. The creative economy: how people make money from ideas. London: Allen Lane, 2013.

IBGE - Instituto Brasileiro de Geografia e Estatística. Cultura, Recreação e Esporte. 2019. Disponível em: https://www.ibge.gov.br/estatisticas/multidominio/culturarecreacao-e-esporte.html. Acesso em: 2 jan. 2021.

ISERNIA, P.; LAMONICA, A. G. The Assessment of the Impact of COVID-19 on the Cultural and Creative Sectors in EU's Partner Countries: Policy Responses, and their Implications for International Cultural Relations. Technical Report, Cultural Relations Platform (EUROPAID/140334/DH/SER/MULTI). 2021. Disponivel em: https://www.cultureinexternalrelations.eu/cier-data/uploads/2021/02/CRP_COVID_ ICR_Stud y-final-Public.pdf. Acesso em: 10 mar. 2021. 


\section{Brazilian \\ Creative Industries}

LANDRY, C. Origens e futuros da cidade criativa. São Paulo: SESI-SP, 2013.

LANDRY, C.; BIANCHINI, F. The Creative City. London: Demos, 1995.

MADUREIRA, A. F. A.; BRANCO, A. U. A pesquisa qualitativa em psicologia do desenvolvimento: questões epistemológicas e implicações metodológicas. Temas em psicologia, v. 9, n. 1, p. 63-75, 2001.

MENDONÇA, M. M. C.; COVAS, A. M. A. Cidades inteligentes e criativas e smartificação dos territórios: apontamentos para reflexão. DRd-Desenvolvimento Regional em debate, v. 10, n. ed. esp., p. 40-59, 2020.

PRATT, A. C. Creative cities: the cultural industriesand the creative class. Geografiska Annaler: Series B, human geography, v. 90, n. 2, p. 107-117, 2008.

REIS, A. C. F. Cidades Criativas. São Paulo: Garimpo de Soluções, 2012.

REIS, A. C. F.; URANI, A. Cidades criativas - perspectivas brasileiras. In: REIS, A. C. F.; KAGEYAMA, P. (Orgs.). Cidades criativas: perspectivas. São Paulo: Garimpo de Soluções, 2011. p. 30-37. Disponível em: https://garimpodesolucoes.com.br/wp-content/uploads/2014/09/Livro_Cidades_Criativas_Perspectivas_v1.pdf. Acesso em: 15 abr. 2021.

REIS, A. C. F. Introdução. In: REIS, A. C. F. (Org.). Economia criativa como estratégia de desenvolvimento: uma visão dos países em desenvolvimento. São Paulo: Itaú Cultural, 2008. p. 15-49. Disponível em: https://garimpodesolucoes.com.br/wp-content/uploads/2014/09/Economia-Criativa-como-Estrat\%C3\%A9gia-de-Desenvolvimento.pdf. Acesso em: 15 abr. 2021.

SANDOVAL, C. G.; ARRUDA, J. S.; SANTOS, N. C. Ouro Preto:Impactos da atividade turística em uma cidade tombada. Itinerarium, v. 2, 2009.

SIMAS, S. C. O. A criatividade como estratégia de competitividade. 2009. 160 f. Dissertação (Mestrado em Gestão da Inovação e do Conhecimento). Universidade de Aveiro, Portugal, 2009.

UNCTAD - United Nations Conference on Trade and Development. Creative Economy Report 2010: A Feasible Development Option, Paris: UNCTAD: 2010. Disponivel em: http://www.unctad.org/Templates/ webflyer.asp?docid=9750\&intltemID =4494\&lang=1\&mo de=downloads. Acesso em: 15 abr. 2021.

UNCTAD - United Nations Conference on Trade and Development. Creative Economy Outlook: Trends in international trade in creative industries 2002-2015, country profiles 2005-2014, Paris: UNCTAD, 2018. Disponível em: https://unctad.org/system/files/official-document/ditcted2018d3_en.pdf. Acesso em: 15 abr. 2021. 


\section{Brazilian Creative Industries}

UNESCO - United Nation Educational, Scientific and Cultural Organization. UNESCO Creative Cities' Response to COVID-19. Paris: UNESCO, 2020. Disponivel em https://unesdoc.unesco.org/ark:/48223/ pf0000374264?posInSet=7\&queryld=1f26fc80-270a-4c54-bb11-17e83ea8888b. Acesso em: 15 abr. 2021.

UNESCO - United Nation Educational, Scientific and Cultural Organization. UNESCO Creative Cities moving towards the 2030 Agenda for Sustainable Development. Paris: UNESCO, 2019. Disponível em: https://en.unesco.org/creative-cities/sites/default/files/16_pages_villes_creatives_uk_bd.pdf. Acesso em: 15 abr. 2021.

VITÓRIA, J. R.; EMMENDOERFER, M. L.; CUNHA, N. R. S.; ARAUJO, J. F. F. E.; MARQUES, L. C. Mudanças institucionais e política pública de economia criativa: o caso de Lisboa? Portugal. Revista inclusiones, Santiago, v. 8, n. 3, p. 01-28, 2021. Disponivel em: http://revistainclusiones.org/index.php/inclu/article/ view/3007. Acesso em: 15 jun. 2021.

VITÓRIA, J. R.; EMMENDOERFER, M. L. Políticas Públicas de Cultura. Salvador: Motres Acadêmicos, 2021. 